\title{
Superstrate-integrated Switchable Beam Rectangular Microstrip Antenna for Gain Enhancement
}

\author{
Supakit KAWDUNGTA ${ }^{1}$, Puwanai JAIBANAUEM ${ }^{1}$, Rattiya PONGGA ${ }^{1}$, \\ Chuwong PHONGCHAROENPANICH ${ }^{2}$ \\ ${ }^{1}$ Faculty of Engineering, Rajamangala University of Technology Lanna, Chiang Mai 50300, Thailand \\ ${ }^{2}$ Faculty of Engineering, King Mongkut's Institute of Technology Ladkrabang, Bangkok 10520, Thailand \\ supakitting@rmutl.ac.th, kpchuwon@kmitl.ac.th,pchuwong@gmail.com \\ Submitted May 1, 2016 / Accepted September 24, 2016
}

\begin{abstract}
This research has proposed a switchable beam rectangular microstrip antenna with double parasitic patches, in which two PIN diodes were deployed for manipulation of the main beam direction and a superstrate (i.e. either a dielectric slab or metamaterial) for enhancement of the antenna gain. The dielectric slab is a second FR4 substrate while the metamaterial (MTM) is the $7 \times 17$ periodic structure of planar cycloid dipoles (PCD). Simulations were carried out and three different antenna prototypes (i.e. the proposed switchable beam rectangular microstrip antenna, the proposed antenna either with dielectric slab or MTM) fabricated and experimented. The simulation and experimental results are in good agreement and exhibit good impedance matching $\left(\left|S_{11}\right|<-10 \mathrm{~dB}\right)$ along the operating frequency. The average measured gain is $7 \mathrm{dBi}$ with the unidirectional radiation pattern along the operating frequency. The proposed switchable antennas with and without the superstrate are operable in the 2.4-2.5 GHz WLAN system and switchable in three directions of $0^{\circ}, 30^{\circ}$ and $330^{\circ}$ (xy-plane). Moreover, the findings validate the applicability of either the dielectric slab or three MTM block-layers as the superstrate to improve the antenna gain.
\end{abstract}

\section{Keywords}

Gain enhancement, metamaterial, microstrip, parasitic patch, PIN diode, switched beam, superstrate

\section{Introduction}

The exponential growth in smartphone use, together with the greater availability of budget internet-connected devices, has contributed to a phenomenon in which the demand for digital wireless communications outstrips the supply (i.e. capacity). In addition, the digital wireless technology suffers from the multipath fading effect where the waves reflect and scatter upon impacting the obstacles. According to [1], [2], these issues could be efficiently addressed with the utilization of a smart antenna, beam steering antenna or switchable beam antenna.

In [1], the authors applied the path-diversity reception technique of the constant modulus algorithm (CMA) to an adaptive array antenna (AAA) to reduce the co-channel interference $(\mathrm{CCI})$ in the terrestrial digital mobile communications. The aim was to efficiently utilize the frequency spectrum. In [2], a smart antenna based on the beamforming technique with spatial diversity using a fuzzy interference system and a neural network (NN) was proposed to reduce the signal loss associated with low beamforming. A genetic algorithm (GA) was used in the optimization of the fuzzy logic and NN, and the technique could achieve a lower side lobe level (SLL) than did the non-algorithmintegrated methods.

By comparison, the switchable beam antenna is less costly and of lower profile. Nevertheless, its beam steering is of discrete fashion. In [3], the switchable beam disc antenna was proposed for a wireless communications network. The main beam of the antenna could be rotated $360^{\circ}$ around the azimuth angle and possesses a wide impedance bandwidth. The four elements of the slot antenna with single feed point were also presented. This antenna controls the main beam by alternating the ON/OFF state of four PIN diodes over the azimuth angle [4].

In [5], the authors proposed a switchable beam antenna using a printed circuit board (PCB) and an FR4 substrate with a square microstrip ring structure. A PIN diode was also utilized to manipulate the radiation pattern. In [6], the authors proposed a single-fed switchable beam antenna using the quasi-Yagi structure and a PIN diode to select an antenna director. Meanwhile, further improvements were made to the switchable beam antenna for the dualband operation $(2.4 \mathrm{GHz}$ and $5.8 \mathrm{GHz})$ [7] using frequency selective surfaces [8]. In addition, several other components have been utilized to manipulate the antenna main beam, e.g. a transistor, field effect transistor (FET), and radio frequency microelectromechanical system (RF MEMS) switch [9], [10].

Wireless communications require a high-gain antenna, especially for the point-to-point and point-to-mul- 
tipoint applications. Many gain improvement techniques have been proposed and experimented, e.g. the multilayer substrates or superstrates in the printed antenna [11], the metamaterial (MTM) to tune the impedance matching [12]. In addition, the multiband loaded monopole was integrated into the MTM to achieve the multiband operation for the WLAN/WiMAX applications [13]. In [14], the MTM was deployed in the design of an array antenna and thereby could suppress the mutual coupling while achieving the higher directivity. Moreover, the MTM was utilized to improve the impedance bandwidth [15], [17].

This current research proposes a switchable beam rectangular microstrip antenna with double parasitic patches. Two PIN diodes are deployed for manipulation of the main beam direction and a superstrate (i.e. either a dielectric slab or metamaterial) for enhancement of the antenna gain. The dielectric slab is a second FR4 substrate while the metamaterial $(\mathrm{MTM})$ is the $7 \times 17$ periodic structure of planar cycloid dipoles (PCD). The proposed switchable antennas with and without the superstrate are operable in the 2.4-2.5 GHz WLAN system and switchable in three directions of $0^{\circ}, 30^{\circ}$ and $330^{\circ}$ ( $x y$-plane).

The organization of this research is as follows: Section 1 is the introduction. Section 2 deals with the proposed metamaterial (MTM), while Section 3 is concerned with the switchable beam antenna structure and design procedure. Section 4 discusses the deployment of the superstrate (either the dielectric slab or the MTM) to enhance the antenna gain. Three different prototype antennas and their respective experimental results are presented in Sec. 5. The concluding remarks are provided in Sec. 6.

\section{The Configuration of Metamaterial (MTM)}

Metamaterials (MTM) are synthetic periodic-structure materials with a negative refractive index $n$ or with negative permittivity $\varepsilon$ and permeability $\mu$. MTM have been utilized in a variety of applications, including in ultrawideband (UWB) antennas, monopole antennas, lens antennas and waveguides [15-17]. For double negative (DNG) media, the thin metal wire (TW) structure and the split ring resonator (SRR) structure are collectively employed for negative $\varepsilon$ and $\mu$.

Figure 1 illustrates the schematic of a planar cycloid dipole (PCD) of the MTM structure functioning as the DNG media. The PCD is fashioned from TW and SRR. In the study, a PCD was simulated under the normal incidence in a waveguide using CST Microwave Studio [18] and, due to its symmetrical characteristic, only $S_{11}$ and $S_{21}$ were investigated [19], [20].

Figure 2(a) illustrates $\left|S_{11}\right|$ and $\left|S_{21}\right|$ in $\mathrm{dB}$ within the frequency range of 1-4 GHz. In Fig. 2(a), $\left|S_{11}\right|$ and $\left|S_{21}\right|$ are at their respective peak and trough at about the frequency of $2.45 \mathrm{GHz}$, where the effective constitutive parameters

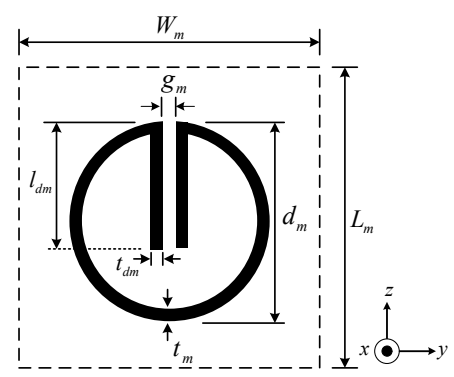

(a)

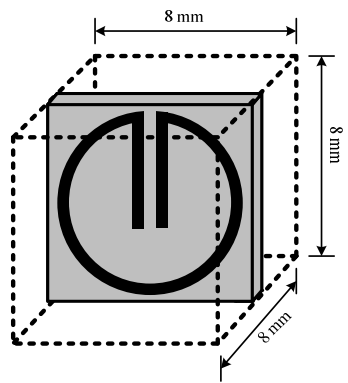

(b)
Fig. 1. The geometry of the planar cycloid dipole: (a) $2 \mathrm{D}$ view, (b) $3 \mathrm{D}$ view.

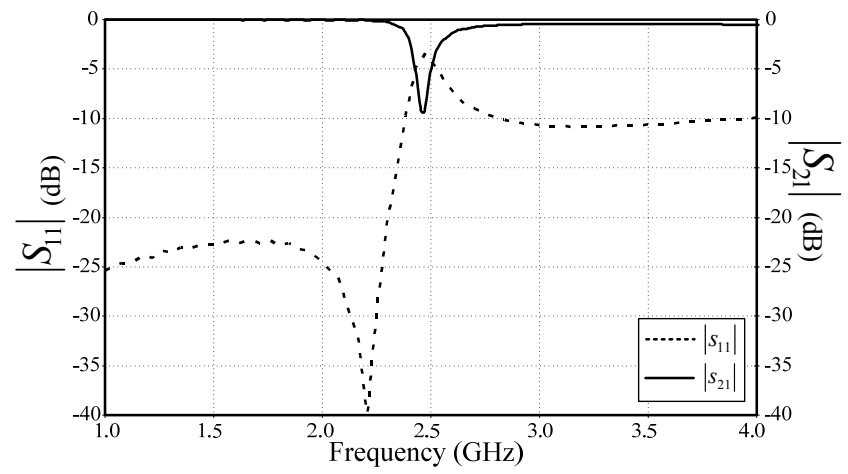

(a)

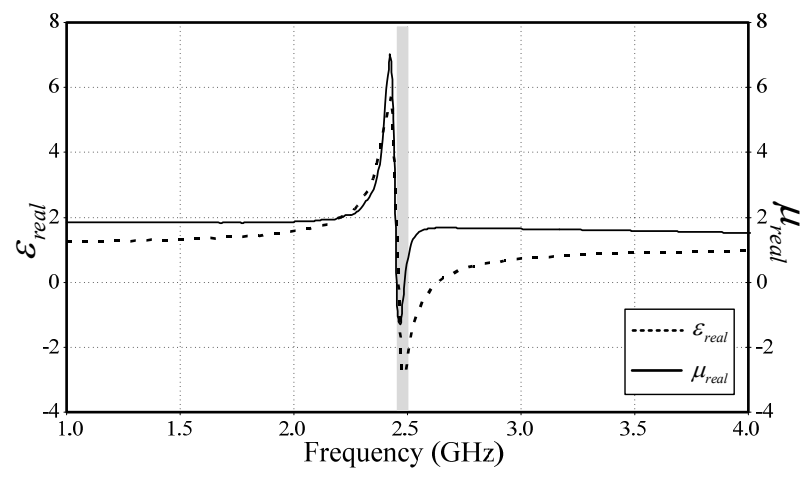

(b)

Fig. 2. The simulated results of the planar cycloid dipole: (a) $\left|S_{11}\right|$ and $\left|S_{21}\right|$ in $\mathrm{dB}$, (b) the real effective permittivity and permeability.

\begin{tabular}{|c|l|c|}
\hline Parameter & \multicolumn{1}{|c|}{ Description } & Physical Size $(\mathrm{mm})$ \\
\hline$W_{m}$ & Total width of MTM & 8.00 \\
\hline$L_{m}$ & Total length of MTM & 8.00 \\
\hline$d_{m}$ & Cycloid diameter & 6.80 \\
\hline$t_{m}$ & Cycloid thickness & 0.20 \\
\hline$g_{m}$ & Distance between two dipoles & 0.20 \\
\hline$t_{d m}$ & Dipole thickness & 0.15 \\
\hline$l_{d m}$ & Dipole length & 5.60 \\
\hline
\end{tabular}

Tab. 1. The parameters and physical dimensions of the planar cycloid dipole.

could be extracted from the $S$ parameters using the Nicolson-Ross-Weir (NRW) method [19], [20].

Based on Tab. 1, the simulated $\left|S_{11}\right|$ and $\left|S_{21}\right|$ were estimated and subsequently extracted for the real effective permittivity and permeability. In its design, the planar cycloid dipole (PCD) is mounted on an FR4 substrate 
$\left(\varepsilon_{\mathrm{r}}=4.3\right)$ with a thickness of $1.8 \mathrm{~mm}$. The simulation results indicated that the real effective permittivity and permeability of the PCD were both negative in the 2.43-2.5 GHz frequency range, as shown in Fig. 2(b).

\section{Switchable Beam Antenna Structure}

Figure 3 illustrates the schematic of the initial rectangular microstrip antenna whose feeding structure is that of a microstrip line. Initially, the microstrip feed line was simulated at the center frequency $f_{\mathrm{r}}$ of $2.45 \mathrm{GHz}$ on an FR4 substrate $\left(\varepsilon_{\mathrm{r}}=4.3\right)$ with a thickness $h$ of $3.2 \mathrm{~mm}$. The design of the feed line was carried out, whereby the patch antenna and the microstrip line match with the characteristic impedance of $50 \Omega$ [21]. The thickness $t$ and length $l_{2}$ of the microstrip line were thus $6.16 \mathrm{~mm}$ and $17 \mathrm{~mm}$, respectively. The position of the feed line was on one edge of the rectangular patch.

Meanwhile, the design of the rectangular patch was carried out using the transmission line model with the dominant mode $\left(\mathrm{TM}_{010}\right)$, as expressed in (1). The initial width $W$ and length $L$ of the rectangular patch were $37.6 \mathrm{~mm}$ and $61.2 \mathrm{~mm}$ (half wavelength) at $2.45 \mathrm{GHz}$.

$$
W=\frac{1}{2 f_{\mathbf{r}} \sqrt{\mu_{0} \varepsilon_{0}}} \sqrt{\frac{2}{\varepsilon_{\mathbf{r}}+1}} .
$$

To simulate, $W$ and $L$ of the radiating patch were varied. It was found that the change in $W$ influenced the resonant frequency. In other words, as the width $W$ increased, the resonant frequency was shifted to the lower frequency. Moreover, simulations were carried out to determine the optimal position of the feed line as it influences the resonant frequency and the polarization of the antenna. The simulation results revealed that, with the feed line positioned in one of the corners, the resonant frequency was subject to $W$ and the polarization was of horizontal direction. On the other hand, with the feed line positioned at the center, the length of the radiating patch $L$ played a significant part in the resonant frequency while the polarization was of vertical direction [21-23]. The chosen dimensions of the radiating patch were thus $27 \mathrm{~mm}$ and $48 \mathrm{~mm}$ for $W$ and $L$, respectively, achieving the resonant frequency at $2.43 \mathrm{GHz}$ with an impedance bandwidth of $70 \mathrm{MHz}\left(\left|S_{11}\right|<-10 \mathrm{~dB}\right)$.

Due to the narrow impedance bandwidth (i.e. $70 \mathrm{MHz}$ ) of the rectangular microstrip antenna and its lowered efficiency as a result of the microstrip feed line, a tuning stub was incorporated into the feed line for improvement of the impedance bandwidth (Fig. 3). In the simulation, $p_{1}, l_{1}$ and $t$ were varied and the results revealed that $p_{1}, l_{1}$ and $t$ of $9.75 \mathrm{~mm}, 9 \mathrm{~mm}$ and $3 \mathrm{~mm}$, respectively, could achieve an impedance bandwidth of $88 \mathrm{MHz}$ with the unidirectional radiation pattern.

In the design of the switchable beam rectangular microstrip antenna, two parasitic patches were individually

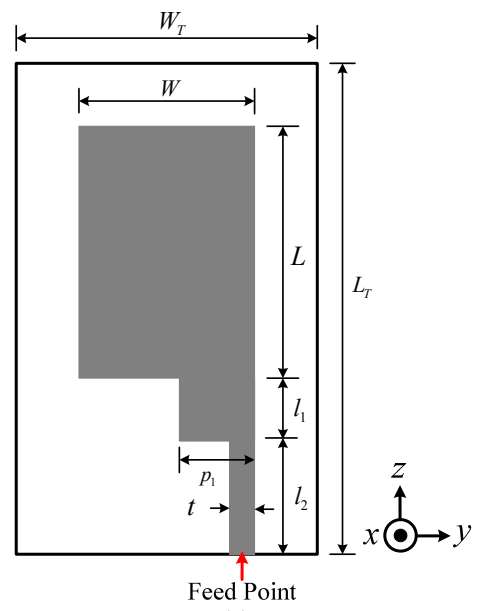

(a)

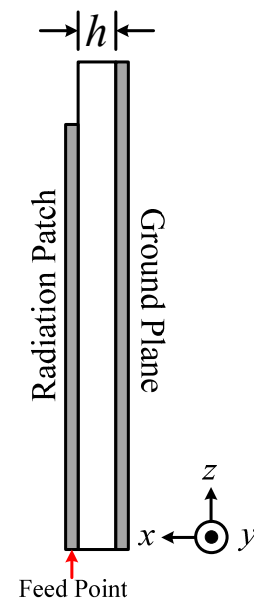

(b)
Fig. 3. The schematic of the rectangular microstrip antenna with tuning stub: (a) Top view, (b) side view.

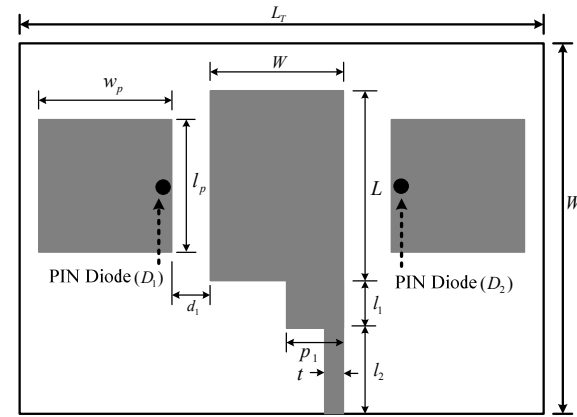

(a)

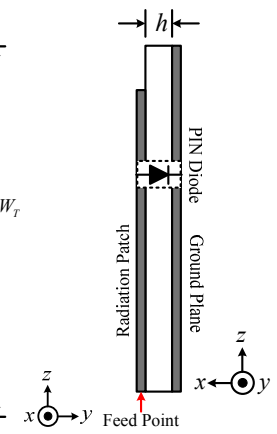

(b)

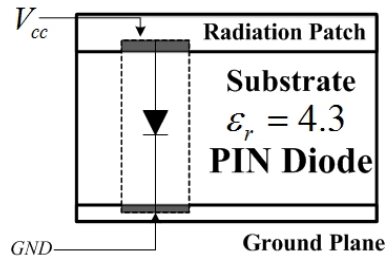

(c)

Fig. 4. The schematic of the switchable beam rectangular microstrip antenna: (a) Top view, (b) Side view, (c) Position of PIN diode.

mounted on either side of the radiating patch (Fig. 4(a)). In principle, the introduction of the parasitic patch influences the impedance of the antenna due to the mutual coupling effect between the parasitic and radiating patches. In addition, the distance between the parasitic and radiating patches dictates the radiation pattern. Moreover, two PIN diodes $\left(D_{1}, D_{2}\right)$ were deployed to short the parasitic patches to the substrate and ground plane. The status of the PIN diodes (i.e. ON or OFF) was manipulated by the DC voltage. Figure 4 illustrates the schematic of the proposed switchable beam rectangular microstrip antenna with double parasitic patches.

Simulations were then carried out and the suitable antenna parameters are tabulated in Tab. 2. In addition, the proposed switchable beam rectangular microstrip antenna with two parasitic patches is operable in three modes: 
mode 1 when both PIN diodes $\left(\mathrm{D}_{1}\right.$ and $\left.\mathrm{D}_{2}\right)$ are OFF, mode 2 when $D_{1}$ is ON while $D_{2}$ is OFF, and mode 3 when $D_{1}$ is $\mathrm{OFF}$ and $\mathrm{D}_{2}$ is $\mathrm{ON}$.

Figure 5(a) compares the simulated $\left|S_{11}\right|$ of the switchable beam rectangular microstrip antenna with double parasitic patches under the three operation modes. The simulated $\left|S_{11}\right|$ varied with the modes of operation but still covered the operating frequency. The $x y$-plane radiation pattern also varied with the variations in the status of the PIN diodes, where the radiation pattern was directed forward under mode 1 and in the left and right directions

\begin{tabular}{|c|l|c|}
\hline $\begin{array}{c}\text { Antenna } \\
\text { Parameter }\end{array}$ & \multicolumn{1}{|c|}{ Description } & Physical Size (mm) \\
\hline$W_{\mathrm{T}}$ & Total width & 90 \\
\hline$L_{\mathrm{T}}$ & Total length & 144 \\
\hline$W$ & Radiation patch width & 26.50 \\
\hline$L$ & Radiation patch length & 48 \\
\hline$p_{1}$ & Tuning stub width & 12 \\
\hline$l_{1}$ & Tuning stub length & 10 \\
\hline$l_{2}$ & Microstrip line length & 17 \\
\hline$t$ & Microstrip line thickness & 3 \\
\hline$d_{1}$ & $\begin{array}{l}\text { Distance between radiation and } \\
\text { parasitic patches }\end{array}$ & 8 \\
\hline$w_{\mathrm{p}}$ & Parasitic patch width & 32 \\
\hline$l_{\mathrm{p}}$ & Parasitic patch length & 30 \\
\hline
\end{tabular}

Tab. 2. The parameters of the proposed switchable beam rectangular microstrip antenna.

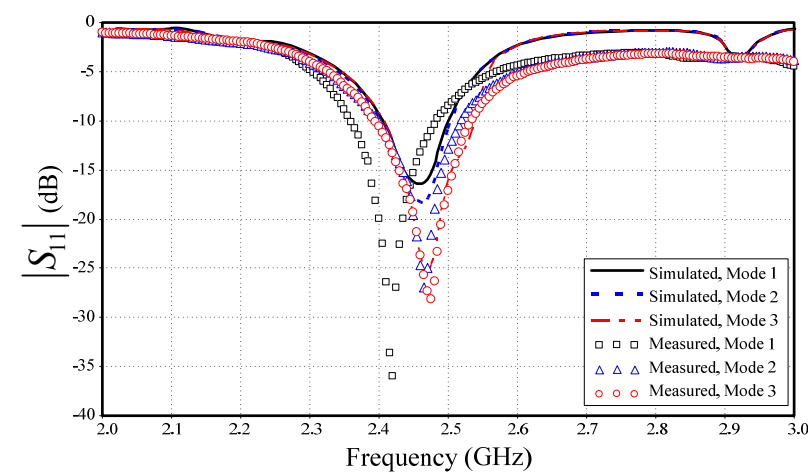

(a)

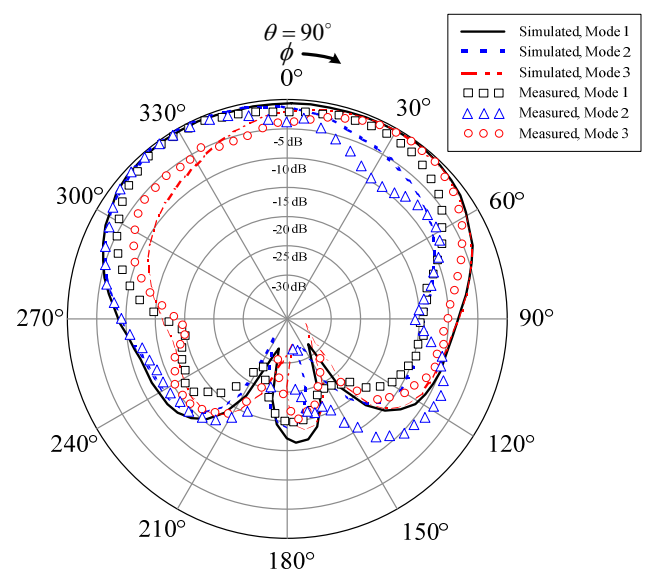

(b)

Fig. 5. Simulated and measured characteristics of the switchable beam rectangular microstrip antenna under three operation modes: (a) $\left|S_{11}\right|$, (b) the $x y$-plane radiation patterns.

\begin{tabular}{|c|c|c|c|c|}
\hline \multirow{2}{*}{ Mode } & \multicolumn{2}{|c|}{ PIN Diodes } & \multirow{2}{*}{$\begin{array}{l}\text { Direction of } \\
\text { Main Beam }\end{array}$} & \multirow{2}{*}{$\begin{array}{l}\text { Maximum } \\
\text { Gain }(\mathrm{dBi})\end{array}$} \\
\hline & $D_{1}$ & $\mathrm{D}_{2}$ & & \\
\hline 1 & OFF & $\mathrm{OFF}$ & $0^{\circ}$ (Center) & 5.6 \\
\hline 2 & $\mathrm{ON}$ & $\mathrm{OFF}$ & $330^{\circ}$ (Left) & 6.7 \\
\hline 3 & OFF & $\mathrm{ON}$ & $30^{\circ}$ (Right) & 6.5 \\
\hline
\end{tabular}

Tab. 3. The simulated performance of the proposed antenna under three operation modes.

under modes 2 and 3, respectively. Figure 5(b) illustrates the $x y$-plane radiation patterns of the switchable beam rectangular microstrip antenna under the three operation modes.

Table 3 summarizes the results of the proposed antenna with regard to the main beam direction and maximum gain under the three operation modes. Under mode 1, the main beam directs at $0^{\circ}$ (center) with HPBW of $120^{\circ}$. The main beam directs at $330^{\circ}$ (left) with HPBW of $60^{\circ}$ under mode 2 and at $30^{\circ}$ (right) with HPBW of $60^{\circ}$ under mode 3. In addition, $\left|S_{11}\right|$ is less than $-10 \mathrm{~dB}$ along the 2.4-2.5 GHz frequency range under all three operation modes.

\section{Gain Enhancement Using Dielectric Slab or MTM}

This section examines the deployment of either a dielectric slab or the MTM as the superstrate for enhancement of the antenna gain. In the first scenario, a dielectric slab (i.e. another FR4 substrate) was introduced and mounted onto the switchable beam rectangular microstrip antenna, forming two additional layers of superstrate: free space $\left(\varepsilon_{\mathrm{r}}=1\right)$ and the additional FR4 $\left(\varepsilon_{\mathrm{r}}=4.3\right)$.

In Fig. 6, the distance between the antenna and the dielectric slab $d$ was varied between $1-11 \mathrm{~mm}$, and the FR4 thickness was either $1.8 \mathrm{~mm}$ or $3.2 \mathrm{~mm}$. It was found that the bandwidth and gain increased with increase in $d$ and that the $3.2 \mathrm{~mm}$-thick FR4 outperformed the $1.8 \mathrm{~mm}$-thick superstrate. Thus, $d$ and the FR4 thickness, respectively, of $10 \mathrm{~mm}$ and $3.2 \mathrm{~mm}$ were adopted for the improved bandwidth (i.e. $132 \mathrm{MHz}$ ) with the maximum gain of $6.2 \mathrm{dBi}$.

Figures 7(a) and (b) respectively illustrate the simulated radiation patterns and $\left|\mathrm{S}_{11}\right|$ of the proposed switchable beam rectangular microstrip antenna with dielectric slab under the three operation modes. The simulation results indicated that the main beam of the proposed antenna with dielectric slab could be manipulated in three directions. Under mode 1 , the main beam was at $0^{\circ}$ (center) with HPBW of $100^{\circ}$, a bandwidth of $132 \mathrm{MHz}$ and a gain of $6.2 \mathrm{dBi}$. Under mode 2, the main beam was at $330^{\circ}$ (left) with $\mathrm{HPBW}$ of $50^{\circ}$, a bandwidth of $130 \mathrm{MHz}$ and a gain of $7.30 \mathrm{dBi}$, while it was at $30^{\circ}$ (right) with $\mathrm{HPBW}$ of $50^{\circ}$, a bandwidth of $135 \mathrm{MHz}$ and a gain of $7.46 \mathrm{dBi}$ under mode 3 . Thus, the dielectric slab could be deployed as the superstrate to improve the bandwidth and gain of the switchable beam rectangular microstrip antenna. 


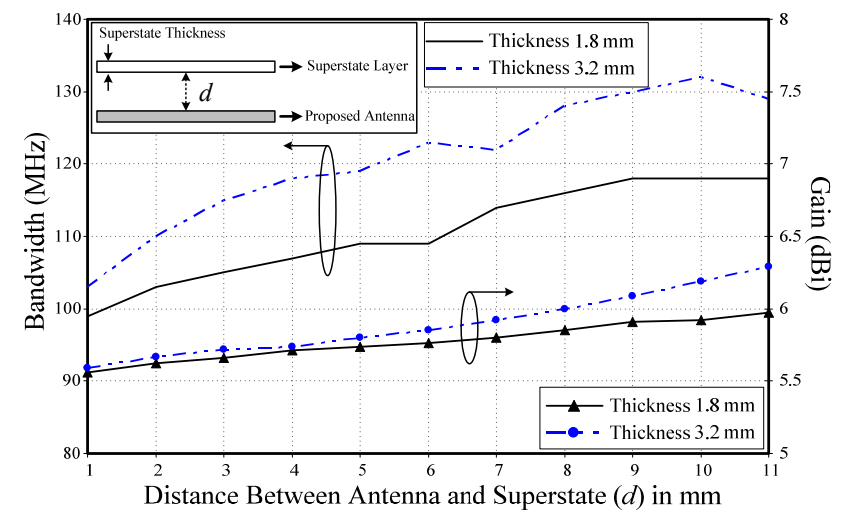

Fig. 6. Simulated bandwidths and gains for various $d$ and two thicknesses of FR4.

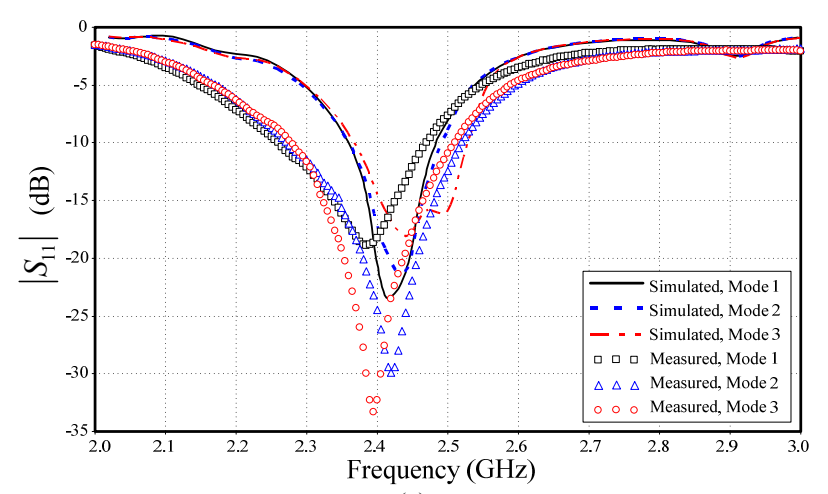

(a)

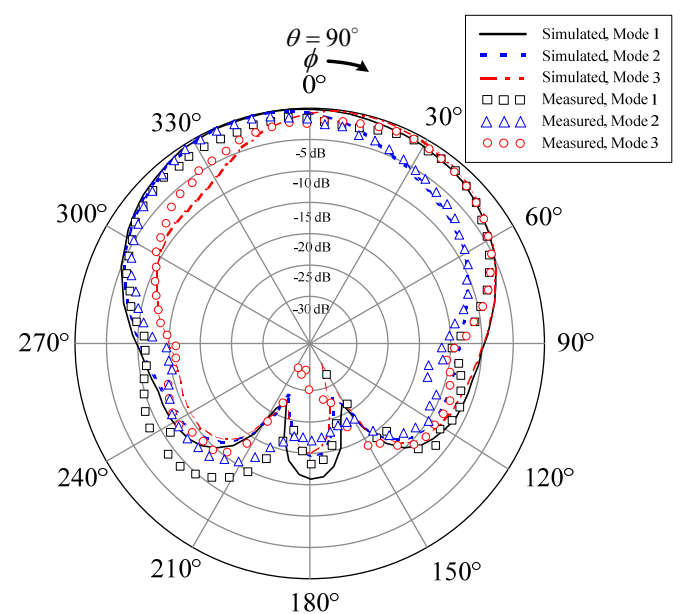

(b)

Fig. 7. Simulated and measured characteristics of the switchable beam rectangular microstrip antenna with dielectric slab under three operation modes: (a) $\left|S_{11}\right|$, (b) $x y$-plane radiation patterns.

In the second scenario, the proposed MTM was utilized as the superstrate of the switchable beam rectangular microstrip antenna to enhance the antenna gain. The MTM was placed in front of the switchable antenna with a distance of $2 \mathrm{~mm}$, as shown in Fig. 8. The arrangement of the planar cycloid diodes (PCD) was such that one MTM block-layer was of $7 \times 17$ periodic structure. Simulations were then carried out by increasing the number of MTM block-layers while observing $\left|S_{11}\right|$ and the radiation pattern (Fig. 9(a)-(b)).

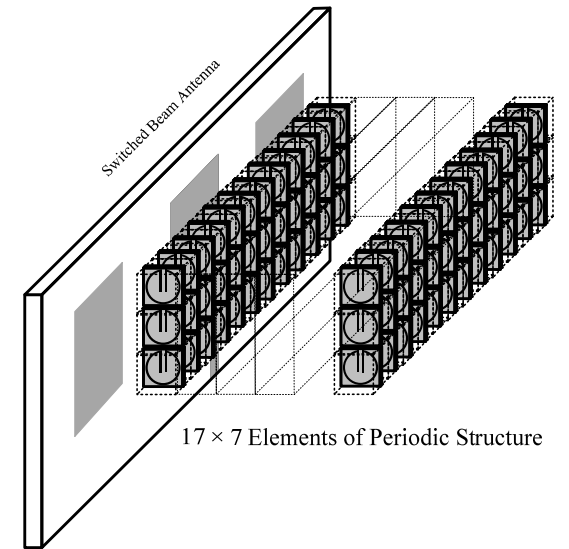

Fig. 8. Depiction of the switchable beam rectangular microstrip antenna with the MTM superstrate.

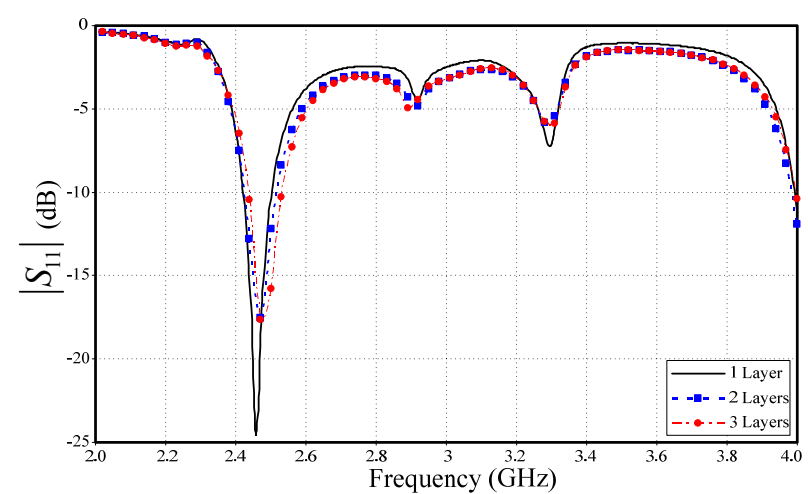

(a)

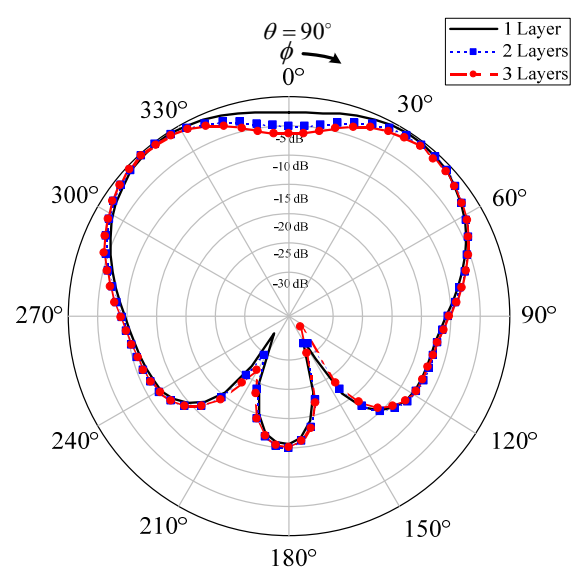

(b)

Fig. 9. The simulated characteristics of the switchable beam rectangular microstrip antenna for various MTM block-layers: (a) $\left|S_{11}\right|$, (b) $x y$-plane radiation patterns.

The simulation results revealed that $\left|S_{11}\right|$ shifted to the higher resonant frequency with increase in the number of MTM block-layers. In addition, the antenna gain increased with increase in the MTM block-layers, while the beamwidth became narrower. This research thus utilized three MTM block-layers so that the final antenna would not be too oversized while achieving the improved antenna gain in relation to the non-MTM antenna.

Further simulations were carried out with the switchable beam rectangular microstrip antenna with three MTM 
block-layers under the three operation modes. Figures 10(a) and (b) respectively illustrate the simulated $\left|S_{11}\right|$ of the MTM-integrated antenna and the radiation patterns under the three operation modes. Specifically, under mode 1 , the main beam directs at $330^{\circ}$ and $30^{\circ}$ with HPBW of $50^{\circ}$, a bandwidth of $130 \mathrm{MHz}$ and a gain of $6.9 \mathrm{dBi}$. Under mode 2, the main beam directs at $330^{\circ}$ (left) with HPBW of $48^{\circ}$, a bandwidth of $130 \mathrm{MHz}$ and a gain of $7.5 \mathrm{dBi}$, while the main beam directs at $30^{\circ}$ (right) with HPBW of $47^{\circ}$, a bandwidth of $135 \mathrm{MHz}$ and a gain of $7.8 \mathrm{dBi}$ under mode 3. Figure 11 shows the radiation efficiency of the three proposed antennas. The trends of the radiation efficiency for these three antennas are decreased when the frequency is higher. The loss of the FR4 substrate causes the degraded radiation efficiency at the higher frequency. At the frequency of $2.45 \mathrm{GHz}$, the radiation efficiency of the proposed antenna is $72 \%$. When this structure is added by either the dielectric slab or MTM, the efficiency is increased to $74.5 \%$. It is obvious that the radiation efficiency of the proposed antenna with either the dielectric slab or MTM is better than the proposed antenna without superstrate. The additional superstrate (dielectric slab or MTM) can improve the radiation efficiency over the relevant range of frequencies because the losses of surface waves are reduced. It is an inherent anisotropy of the additional structure and back-ward wave in superstrate.

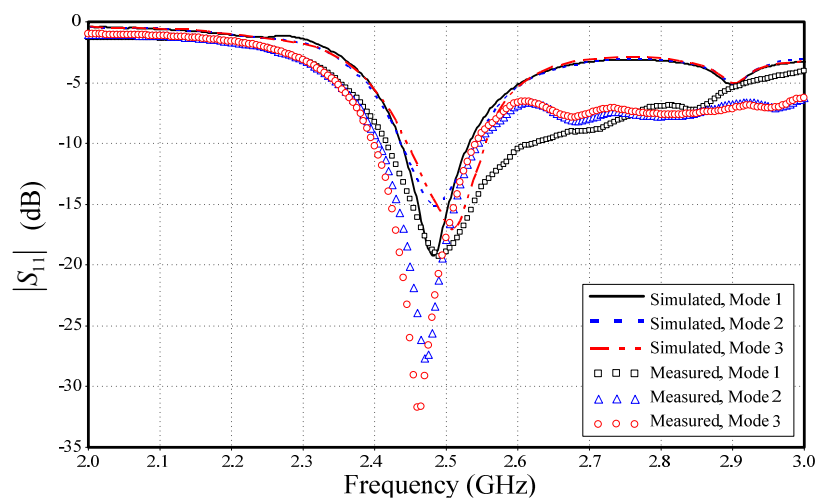

(a)

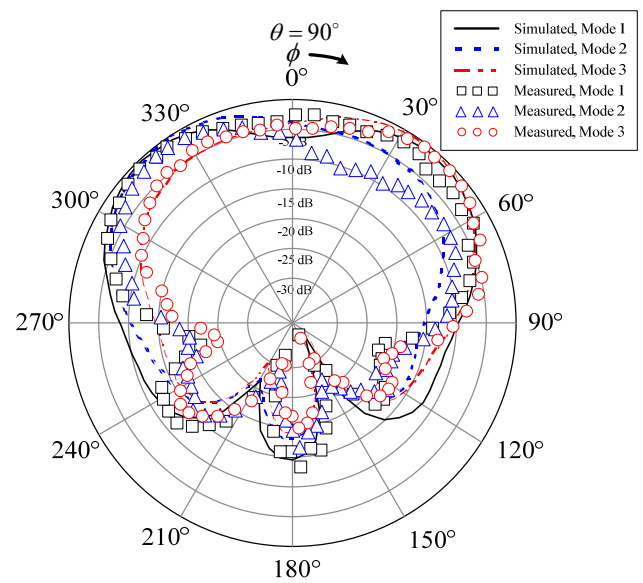

(b)

Fig. 10. The simulated and measured characteristics of the switchable beam rectangular microstrip antenna with three MTM block-layers under three operation modes: (a) $\left|S_{11}\right|$, (b) $x y$-plane radiation patterns.

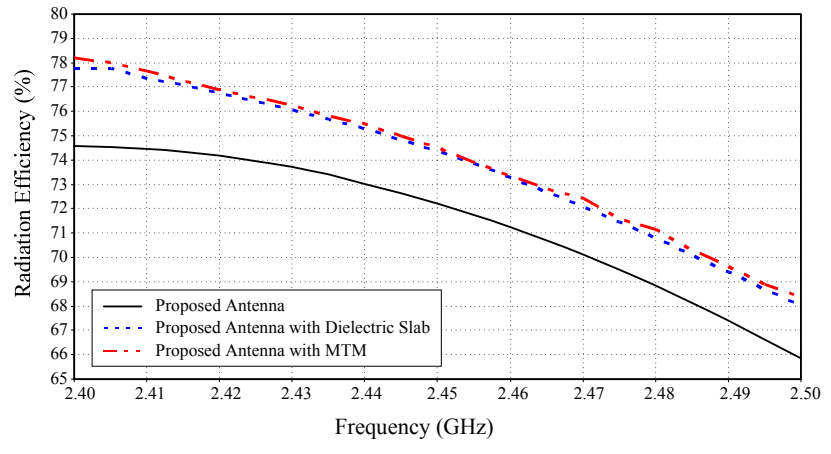

Fig. 11. The simulated radiation efficiency of the three proposed antennas.

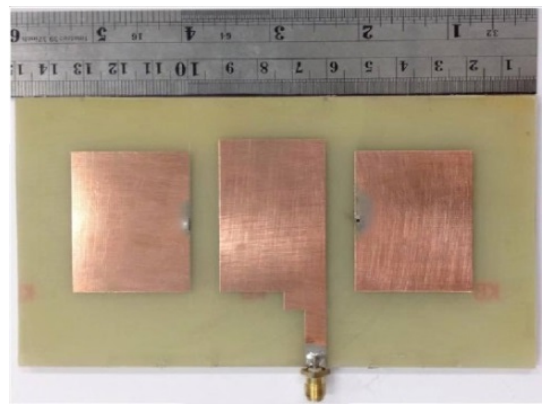

Fig. 12. Prototype of the switchable beam rectangular microstrip antenna.

\section{Experimental Results}

To verify, three prototype antennas were fabricated and experiments undertaken. The three prototype antennas were the proposed switchable beam rectangular microstrip antenna, the proposed antenna with either the dielectric slab or MTM.

Figure 12 depicts the prototype of the switchable beam rectangular microstrip antenna with two parasitic patches on a $3.2 \mathrm{~mm}$-thick FR4 substrate $\left(\varepsilon_{\mathrm{r}}=4.3\right)$. Two PIN diodes with $R_{\text {on }}$ of $1.8 \Omega$ and $C_{\text {on }}$ of $9.3 \mathrm{pF}$ were deployed to affix the parasitic patches to the substrate and the ground plane. The experimental results revealed that the proposed switchable beam rectangular microstrip antenna could achieve a bandwidth of $120 \mathrm{MHz}$. In addition, the $x y$-plane radiation patterns under the three operation modes were as follows: under mode 1, the direction of the main beam was of $0^{\circ}$ with HPBW of $120^{\circ}$ and the maximum gain of $5.6 \mathrm{dBi}$; under mode 2 , the direction was of $330^{\circ}$ with HPBW of $60^{\circ}$ and the maximum gain of $6.7 \mathrm{dBi}$; and under mode 3 , the direction was of $30^{\circ}$ with HPBW of $60^{\circ}$ and the maximum gain of $6.5 \mathrm{dBi}$ (Fig. 5(a), (b)).

The second prototype antenna was the switchable beam rectangular microstrip antenna with dielectric slab as the superstrate with the distance between the antenna and the slab of $10 \mathrm{~mm}$. This antenna dimension is $90 \mathrm{~mm} \times 144 \mathrm{~mm} \times 16.4 \mathrm{~mm}$. In Fig. 7(a), the prototype antenna with the dielectric slab could achieve a bandwidth of $200 \mathrm{MHz}$. In addition, the $x y$-plane radiation patterns under the 3 operation modes are as follows: under mode 1 


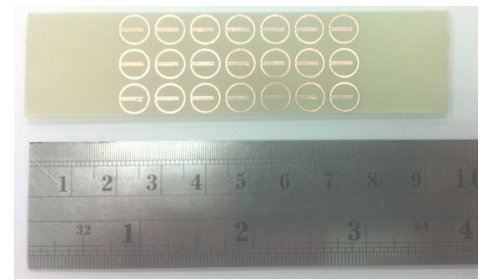

Fig. 13. Periodic structure of planar cycloid dipoles.

the direction of the main beam was of $0^{\circ}$ with $\mathrm{HPBW}$ of $100^{\circ}$ and the maximum gain of $6.2 \mathrm{dBi}$; under mode 2 , the direction was of $330^{\circ}$ with HPBW of $50^{\circ}$ and the maximum gain of $7.3 \mathrm{dBi}$; and under mode 3 , the direction was of $30^{\circ}$ with $\mathrm{HPBW}$ of $50^{\circ}$ and the maximum gain of $7.46 \mathrm{dBi}$ (Fig. 7(b)).

The third prototype antenna was the switchable beam rectangular microstrip antenna with three MTM blocklayers, as shown in Fig. 13. The antenna size is $90 \mathrm{~mm} \times 144 \mathrm{~mm} \times 29.2 \mathrm{~mm}$. The prototype antenna with three MTM block-layers could achieve a bandwidth of $150 \mathrm{MHz}$. The $x y$-plane radiation patterns under the three operation modes are as follows: under mode 1, the directions of the main beam were of $30^{\circ}$ and $330^{\circ}$ with HPBW of $50^{\circ}$ and the maximum gain of $6.9 \mathrm{dBi}$; under mode 2 , the direction was of $330^{\circ}$ with HPBW of $48^{\circ}$ and the maximum gain of $7.5 \mathrm{dBi}$; and under mode 3 , the direction was of $30^{\circ}$ with HPBW of $47^{\circ}$ and the maximum gain of $7.8 \mathrm{dBi}$ (Fig. 10(a), (b)).
The measured results indicated that the switchable beam rectangular microstrip antennas of all three configurations were operable under all three operation modes along the $2.4-2.5 \mathrm{GHz}$ frequency range. Table 4 compares the performances of the three prototype antennas and it is evident that the deployment of either the dielectric slab or MTM as the superstrate could enhance the antenna gain.

\section{Conclusions}

This research has presented the switchable beam rectangular microstrip antenna in which two PIN diodes were deployed for manipulation of the main beam direction and the superstrate (i.e. either a dielectric slab or the MTM) for enhancement of the antenna gain. In this research, the dielectric slab is a second FR4 substrate while the metamaterial (MTM) is the $7 \times 17$ periodic structure of planar cycloid dipoles (PCD). The proposed switchable antennas with and without the superstrate are operable in the 2.4-2.5 GHz WLAN system and switchable in three directions of $0^{\circ}, 30^{\circ}$ and $330^{\circ}$ ( $x y$-plane). The simulation and experimental results validate the applicability of the dielectric slab and three MTM block-layers as the superstrate to improve the antenna gain. In addition, the proposed superstrate-integrated switchable beam rectangular microstrip antenna could be employed in the point-to-point and point-to-multipoint applications.

\begin{tabular}{|c|c|c|c|c|c|c|c|c|c|}
\hline \multirow{3}{*}{ Mode } & \multicolumn{3}{|c|}{ Prototype Antenna } & \multicolumn{3}{c|}{ Prototype Antenna with Dielectric Slab } & \multicolumn{3}{c|}{ Prototype Antenna with MTM } \\
\cline { 2 - 10 } & $\begin{array}{c}\text { Direction of } \\
\text { Main Beam }\end{array}$ & HPBW & $\begin{array}{c}\text { Maximum } \\
\text { Gain (dBi) }\end{array}$ & $\begin{array}{c}\text { Direction of } \\
\text { Main Beam }\end{array}$ & HPBW & $\begin{array}{c}\text { Maximum } \\
\text { Gain (dBi) }\end{array}$ & $\begin{array}{c}\text { Direction of } \\
\text { Main Beam }\end{array}$ & $\begin{array}{c}\text { HPBW } \\
\text { Maximum } \\
\text { Gain (dBi) }\end{array}$ \\
\hline 1 & $0^{\circ}$ & $120^{\circ}$ & 5.6 & $0^{\circ}$ & $100^{\circ}$ & 6.2 & $330^{\circ}$ and $30^{\circ}$ & $50^{\circ}$ & 6.9 \\
\hline 2 & $330^{\circ}$ & $60^{\circ}$ & 6.7 & $330^{\circ}$ & $50^{\circ}$ & 7.3 & $330^{\circ}$ & $48^{\circ}$ & 7.5 \\
\hline 3 & $30^{\circ}$ & $60^{\circ}$ & 6.5 & $30^{\circ}$ & $50^{\circ}$ & 7.46 & $30^{\circ}$ & $47^{\circ}$ & 7.8 \\
\hline
\end{tabular}

Tab. 4. Comparison of the measured results of the three prototype antennas under three operation modes.

\section{Acknowledgments}

The authors would like to express deep gratitude to Rajamangala University of Technology Lanna for the financial sponsorship under the Hands-on Research and Development Project (UR-17).

\section{References}

[1] FURUKAWA, H., KAMIO, Y., SASAOKA, H. Cochannel interference reduction and path-diversity reception technique using CMA adaptive array antenna in digital land mobile communications. IEEE Transactions on Vehicular Technology, 2001, vol. 50, no. 2, p. 605-616. DOI: 10.1109/25.923072

[2] GHOUSE BASHA, T. S., ALOYSIUS, G., RAJAKUMAR, B. R., GIRI PRASAD, M. N., SRIDEVI, P. V. A constructive smart antenna beam-forming technique with spatial diversity. IET Microwaves, Antennas and Propagation, 2012, vol. 6, no. 7, p. 773 - 780. DOI: 10.1049 /iet-map.2011.0356

[3] CERRI, G., LEO, R. D., PRIMIANI, V. M., MONTEVERDE, C.,
RUSSO, P. Design and prototyping of a switching beam disc antenna for wideband communications. IEEE Transactions on Antennas and Propagation, 2006, vol. 54, no. 12, p. 3721-3726. DOI: 10.1109 /TAP.2006.886555

[4] LAI, M.-I., WU, T.-Y., HSIEH, J.-C., WANG, C.-H., JENG, S.-K. Compact switched-beam antenna employing a four-element slot antenna array for digital home applications. IEEE Transactions on Antennas and Propagation, 2008, vol. 56, no. 9, p. 2929-2936. DOI: $10.1109 /$ TAP.2008.928775

[5] SHYNU NAIR, S. V., AMMANN, M. J. Reconfigurable antenna with elevation and azimuth beam switching. IEEE Antennas and Wireless Propagation Letters, 2010, vol. 9, p. 367-370. DOI: 10.1109/LAWP.2010.2049332

[6] QIN, P.-Y., GUO, Y. J., DING, C. A beam switching quasi-Yagi dipole antenna. IEEE Transactions on Antennas and Propagation, 2013, vol. 61, no. 10, p. 4891-4899. DOI: 10.1109/TAP.2013.2274635

[7] NOR, M. Z. M., RAHIM, S. K. A., SABRAN, M. I., SOH, P. J., VANDENBOSCH, G. A. E. Dual-band, switched-beam, reconfigurable antenna for WLAN applications. IEEE Antennas and Wireless Propagation Letters, 2013, vol. 12, p. 1500-1503. DOI: 10.1109/LAWP.2013.2289919

[8] EDALATI, A., DENIDNI, T. A. Frequency selective surfaces for 
beam-switching applications. IEEE Transactions on Antennas and Propagation, 2013, vol. 61, no. 1, p. 195-200. DOI: 10.1109/TAP.2012.2219842

[9] CHENG, S., RANTAKARI, P., MALMQVIST, R., SAMUELSSON, C., VAHA-HEIKKILA, T., RYDBERG, A., VARIS, J. Switched beam antenna based on RF MEMS SPDT switch on quartz substrate. IEEE Antennas and Wireless Propagation Letters, 2009, vol. 8, p. 383-386. DOI: 10.1109/LAWP.2009.2018712

[10] REBEIZ, G. M., RF MEMS: Theory, Design and Technology. New York: Wiley, 2003. ISBN: 0471201693

[11] YANG, H. Y., ALEXOPOULOS, N. G. Gain enhancement methods for printed circuit antennas through multiple superstrates. IEEE Transactions on Antennas and Propagation, 1987, vol. 35, no. 7, p. 860-864. DOI: 10.1109/TAP.1987.1144186

[12] SELVANAYAgAM, M., ElEFTHERIADES, G. V. A compact printed antenna with an embedded double-tuned metamaterial matching network. IEEE Transactions on Antennas and Propagation, 2010, vol. 58, no. 7, p. 2354-2361. DOI: 10.1109/TAP.2010.2048876

[13] HUANG, H., LIU, Y., ZHANG, S., GONG, S. Multiband metamaterial-loaded monopole antenna for WLAN/WiMAX applications. IEEE Antennas and Wireless Propagation Letters, 2015, vol. 14, p. 662-665. DOI: 10.1109/LAWP.2014.2376969

[14] BUELL, K., MOSALLAEI, H., SARABANDI, K. Metamaterial insulator enabled superdirective Array. IEEE Transactions on Antennas and Propagation, 2007, vol. 55, no. 4, p. 1074-1085. DOI: $10.1109 /$ TAP.2007.893373

[15] PANDEY, G. K., SINGH, H. S., BHARTI, P. K., MESHRAM, M. K. Metamaterial-based UWB antenna. Electronics Letters, 2014, vol. 50 , no. 18 , p. 1266-1268. DOI: 10.1049/el.2014.2366

[16] ANTONIADES, M. A., ELEFTHERIADES, G. V. A broadband dual-mode monopole antenna using NRI-TL metamaterial loading. IEEE Antennas and Wireless Propagation Letters, 2009, vol. 8, p. 258-261. DOI: 10.1109/LAWP.2009.2014402

[17] CALOZ, C., ITOH, T. Electromagnetic Metamaterials: Transmission Line Theory and Microwave Applications. John Wiley \& Sons, 2006. ISBN: 978-0-471-66985-2

[18] CST Microwave Studio, User's Manual.

[19] ZIOLKOWSKI, R. W. Design, fabrication, and testing of double negative metamaterials. IEEE Transactions on Antennas and Propagation, 2003, vol. 51, no. 7, p. 1516-1529. DOI: 10.1109/TAP.2003.813622

[20] WU, B.-I., WANG, W., PACHECO, J., CHEN, X., GRZEGORCZYK, T., KONG, J. A. A study of using metamaterials as antenna substrate to enhance gain. Progress In Electromagnetics Research, 2005, PIER 51, p. 295-328. DOI: 10.2528/PIER04070701

[21] BALANIS, C. A., Antenna Theory: Analysis and Design. 3rd ed., John Wiley \& Sons, 2005. ISBN: 978-0-471-66782-7

[22] CHEN, W.-L., WANG, G.-M. Small size edge-fed Sierpinski carpet microstrip patch antennas. Progress In Electromagnetics Research C, 2008, vol. 3, p. 195-202. DOI: 10.2528/PIERC08050302

[23] POZAR, D. M., VODA, S. M. A rigorous analysis of a microstripline fed patch antenna. IEEE Transactions on Antennas and Propagation, 1987, vol. 35 , no. 12, p. 1343-1350. DOI: 10.1109/TAP.1987.1144041
[24] SABAPATHY, T., JAMLOS, M. F., AHMAD, R. B., JUSOH, M., JAIS, M. I., KAMARUDIN, M. R. Electronically reconfigurable beam steering antenna using embedded RF pin based parasitic arrays (ERPPA). Progress In Electromagnetics Research, 2013, vol. 140, p. 241-261. DOI: 10.2528/PIER13042906

\section{About the Authors ...}

Supakit KAWDUNGTA received the Bachelor of Engineering (2006) in Telecommunications Engineering, Master of Engineering (2007) in Telecommunications Engineering and Doctor of Engineering (2011) in Electrical Engineering from King Mongkut's Institute of Technology Ladkrabang, Bangkok, Thailand. From 2011 to present, he is an Assistant Professor in electronic and telecommunications engineering, Rajamangala University of Technology Lanna, Chiang Mai, Thailand.

Puwanai JAIBANAUEM received the Bachelor of Engineering (2016) in Electronic Engineering from Rajamangala University of Technology Lanna, Chiang Mai, Thailand. From 2016 to present, he is an engineer in Advanced Info Service PLC., Chiang Mai, Thailand.

Rattiya PONGGA received the Bachelor of Engineering (2015) in Electronic Engineering from Rajamangala University of Technology Lanna, Chiang Mai, Thailand. From 2015 to present, she is an engineer in Thai NJR Co., Ltd., Lamphun, Thailand.

Chuwong PHONGCHAROENPANICH received the Bachelor of Engineering (Hons), Master of Engineering, and Doctor of Engineering degrees from the Faculty of Engineering, King Mongkut's Institute of Technology Ladkrabang (KMITL), Bangkok, Thailand, in 1996, 1998, and 2001, respectively. He is currently an Associate Professor at the Department of Telecommunications Engineering, KMITL where he also serves as the Leader of the Wireless Communication Laboratory at the same institute. He was the board committee of ECTI Association in 2008-2011. He serves as the chair of IEEE MTT/AP/ED Thailand chapter. He is the associate editor of IEICE Trans. Com. and ECTI Trans. EEC. He has been the organizing committee of several international conferences including the TPC chair of 2009 International Symposium on Antennas and Propagation (ISAP2009) and TPC member of ISAP2012. He is the reviewer of many journals including IEEE Trans. Antennas and Propagation and Electronics Letters, ECTI Trans. and many international conferences including ISAP and Asia-Pacific Microwave Conference (APMC). His research interests are antenna design for various mobile and wireless communications, conformal antennas and array antenna theory. Dr. Phongcharoenpanich is a Member of IEEE, IEICE and ECTI. 